\title{
Using COCA to Foster Students' Use of English Collocations in Academic Writing
}

\section{Mansour, Deena Mohammad}

The American University in Cairo, Egypt.

\begin{abstract}
Using Corpora in foreign language teaching is on the very efficient ways in proposing solutions for pedagogical issues, either through adopting a corpus-based teaching approach or through using the corpus in developing material. Developing academic writing competence is a challenging pedagogical issue for English teachers as well as learners. Second language learners come across considerable challenges as they are developing their academic writing competence. One of these challenges is the use of English collocations since that learning about collocations is of a crucial importance. Hence, due to the wide variety of collocations and their different types, one of the challenges that face both L2 learners of English as well as teachers is how to use English collocations successfully in academic writing due to the fact that collocational awareness and proficiency is a necessity for competent written discourse especially in academic writing. Therefore, academic writing proficiency is one of the major problematic areas that university students encounter. This paper focuses on how to direct students to a more effective use of Corpus of Contemporary American English (COCA) in order to foster their learning process of different English collocations, and use English collocations accurately in their academic writings. This paper illustrates search mechanisms and search strings that could be implemented effectively on COCA to get more representative and accurate collocation results.
\end{abstract}

Keywords: corpus, academic writing, collocations, COCA 


\section{Introduction: Online Corpora \& COCA}

The existence of online corpora in the field of applied linguistics significantly changed all the perceptions and approaches of most researchers in the modern age. Using online corpora in teaching and developing material is no longer a luxury as people have thought; it became a necessity and an efficient way to take second language pedagogy into the new digital era. Mark Davis' 520-million-word Corpus of Contemporary American English (COCA) is the richest freely searchable online corpus for its wide range of texts that are from different genres. It can be efficiently used to propose solutions for many pedagogical challenges that face language teachers and leaners with respect to English collocations. As far as academic writing is concerned, English learners find difficulties when using collocations. There are two common mistakes university students tend to make in academic writing: incorrect or inaccurate use of collocations or using a collocation that is too informal to be used in an academic writing. In this paper, the researcher will introduce different search mechanisms and search strings that enhanced university students' ability to analyze their collocation errors and find accurate collocates in the academic sub corpus of COCA.

\section{Literature Review}

Teaching academic writing has been a major concern of academic research recently. Some studies suggested new frameworks and techniques for teaching academic writing, and some other studies directed the attention to the use of corpora in teaching writing in general, and academic writing in particular. Some studies conducted experimental research to test the corpus-based teaching approach on a number of students and observe the impact of using the corpora on their language proficiency. Other studies used the corpus to develop material for teaching English and created word lists to help students improve their language competence. Alex Gilmore (2009) found that free online corpora helped students have more natural writing. He investigated whether training a number of intermediate Japanese university students to use the BNC and COBUILD online corpora will effectively enhance writing second drafts of their academic essays or not. He also explored their reactions and preferences after using these online corpora. In this study, the corpora were used basically to help students correct grammatical problems occurred in their first draft. The results showed that students produced more natural texts in the second draft, and the problematic areas highlighted in the first draft were mostly corrected. Gilmore concluded that the use of the corpora can have an effective role in enhancing writing skills. He also found that using the online corpora does appeal more to visual students who are more analytic and logical. However, L2 learners should receive an appropriate and sufficient training in order to be able to use the corpora effectively. 
Applying the use of corpus-based teaching approach on an experimental group and investigating the impact on students' performance is a significant turning point in the literature of corpus linguistics. Jafarpour et al (2013) compared the effect of a corpus-based teaching of collocations applied on an experimental group to that of traditional approach applied on a control group. The researchers focused on teaching collocations of nearsynonymous pairs. They concluded that the corpus-based approach in teaching collocations outperform the traditional ways. The researchers used concordance materials retrieved from the BNC corpus, and collocations have been taught in context. Jafarpour et al found that their corpus-based teaching approach had a significant effect on the students' knowledge and competence of collocations in the experimental group. According to Jafarpour et al (2013), student in both groups achieved a considerable progress; however, students in the experimental group showed a significant improvement in their writing proficiency after using the corpus producing more authentic language.

Likewise, Yoon (2008) investigated the progress in students' writing performance with corpus use, and how their writing competence has been influenced. Yoon investigated six case studies of L2 students in an English for Academic Purposes course. The results showed that the use of the corpus had a significant and instant impact on the students' writing competence and helped them find immediate solutions for language problems they might have encountered. The participants' writing process went through some minor changes after using the corpus, yet they are effective. In addition, this corpus-based approach developed the students' perceptions of lexicogrammar and language awareness. Another significant finding in Yoon's study was that the students became more autonomous learners taking more responsibility of their learning process and correcting their own mistakes due to their corpus experience.

Focusing on English for academic purposes (EAP), Lee and Swales (2006) conducted their qualitative research testing the use of corpora in a customized EAP course for doctoral students using a special corpus for academic writing and speaking. Students in this study compared their own academic writing to those of more experienced academic writers, and they provided reports discussing their findings of these comparisons and how the use of the corpus can influence their academic writing in the future. As the authors stated, this approach can be specifically of benefit for academic students who are writing their theses and need to develop their styles and academic competence through looking up an academic specialized corpus of their field (Lee \& Swales, 2006). The participants' feedback was very positive that they found that using the corpus is 'confidence-building and empowering', and they also found the corpora much more useful and effective than reference and grammar books. The study proved to be very efficient that most of the participants bought their own versions of Wordsmith concordancing software to use it after the course. 
In a more field-oriented study, Walker (2011) used the Bank of English corpus (BoE) and the British National Commercial Corpus (BNCc) for teaching business English. Walker stated that business English teachers encounter many questions that require answers and conducting some research. Walker suggested that such questions can be answered through investigating the 'collocational behavior' of specific key lexis; this can reveal all the different senses of a word and the other words that co-occur with it in a specific context. Applying a corpus-based teaching approach in two case studies, Walker reaches a conclusion that most collocations are not merely random combinations of words; it is the significantly frequent collocates that show the different meanings and uses of a word. In addition, using corpus here helps to reveal whether there are any negative connotations associated with the collocation (Walker, 2011). Hence, combining collocation lists would play an invaluable role in improving learners' language competence.

Very specifically, Daskalovska (2015) investigated the activities based on corpus for learning verb-adverb collocations in a comparison to the course book regular activities. The results of the study show that the students who used the online concordancer performed much better in the test they took. The findings of this study highlighted how motivating and engaging the corpus-based activities were to the students. The researcher concluded here that the online corpus is a very dynamic and influential tool that has its positive impact on the L2 learners.

Literature illustrates how influential is using online corpora in teaching English as a second language. However, this paper takes a different and more practical approach regarding corpus-based teaching which is exploring different mechanisms and search strings that could effectively retrieve more accurate results when looking up a collocate in an academic context.

\section{Collocates Search on COCA}

COCA search options give users multiple chances to check different types of collocations. The most common colocations that are usually looked up: verb-noun collocations, adjective-noun collocations, adverb-verb collocations, verb-preposition collocations, and adverb-adjective collocations. The current paper discusses a number of search mechanisms that are used on COCA and yielded positive results. The search mechanisms proposed in the current paper have been examined in two different academic language classes. They have been first examined for error analysis in translation classes, and second in an academic essay writing class. There are different sub corpora within the COCA; the one that I focus on in the present paper is the academic sub corpus. The suggested search strings in the present paper raised my translation students' awareness of their errors and helped them correct these errors and find accurate collocations when they translate academic texts from 
Arabic into English. Likewise, using the proposed search strings fostered the students' writing performance in my academic writing class.

There are two ways of conducting collocate searches on COCA: either to use the default list option or to use the collocates option to limit the results. Table 1 illustrates possible search strings that can be conducted to check different types of collocations using the collocates option and the (POS) list which is available in the search engine on the corpus to specify the part of speech that will to be looked up. Academic sub corpus must be checked first in order to get specific results from the academic corpus.

Table 1. Proposed search strings using the list display option

\begin{tabular}{|c|c|c|}
\hline Collocation & Search String & Examples \\
\hline verb-noun & $\begin{array}{l}\text { [verb].[nn] } \\
\text { ex. decline_nn* }\end{array}$ & $\begin{array}{l}\text { (decline) with age/(decline) over } \\
\text { time/(decline) the offer } \\
\text { (conduct) research/ investigations/ } \\
\text { interviews }\end{array}$ \\
\hline adjective-noun & $\begin{array}{l}\text { [adjective].[nn] } \\
\text { ex. } \_ \text {j* results }\end{array}$ & $\begin{array}{l}\text { current/preliminary/ significant } \\
\text { (results) } \\
\text { important/ profound/ long-term } \\
\text { (implications) }\end{array}$ \\
\hline adverb-verb & $\begin{array}{l}\text { [adverb].[v] } \\
\text { ex._r* update }\end{array}$ & $\begin{array}{l}\text { regulary/ constantly/ peri-odically } \\
\text { (update) } \\
\text { critically/ carefully/ properly } \\
\text { (evaluate) }\end{array}$ \\
\hline adverb-adjectve & $\begin{array}{l}\text { [adverb].[j] } \\
\text { ex._r* significant }\end{array}$ & $\begin{array}{l}\text { statistically/particularly/potentially } \\
\text { (significant) } \\
\text { perfectly/ barely/minimally (adequate) }\end{array}$ \\
\hline verb-preposition & $\begin{array}{l}\text { [verb].[prep] } \\
\text { ex. rise _i* }\end{array}$ & $\begin{array}{l}\text { (rise) to/in/from } \\
\text { (express) in/about/to }\end{array}$ \\
\hline
\end{tabular}


The search mechanisms and search strings proposed in the current paper have been practiced with my translation students as well as the academic essay writing students. Applying the suggested search stings on COCA enhanced translation students' performance in their translations from Arabic into English. They started to use accurate collocates in their translations of academic texts. Similarly, the academic essay writing students started to use accurate collocates which are also more academic-related. The errors of using English collocates have been significantly declined in both groups after implementing the suggested search mechanisms on COCA.

Another mechanism could be implemented to look up collocations using the collocates display option available on the corpus. Using this option, there is a tab for the target word which the student/learner needs to look up its collocates. The part of speech of the target word should be specified using the (POS) list. Likewise, the part of speech of the collocates that would be looked up should be specified using the (POS) list as it is displayed in Figure 1. The valuable option here is that the student/learner could limit the search to either the collocates occurring before the word or the words occurring after, or both. In Figure 1, I specified the search to the two words occurring after the target word.

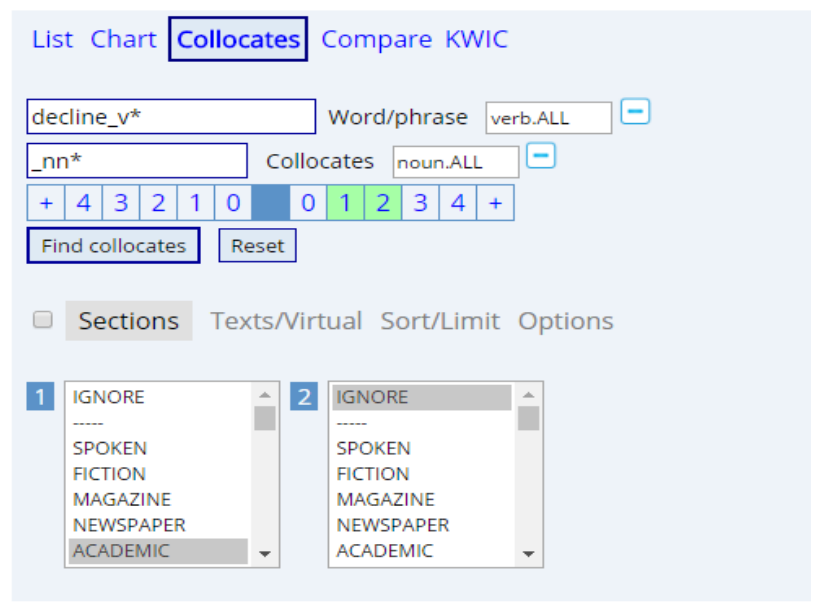

Figure 1. looking up collocations on COCA using the collocates display option

There is another option that many students find valuable when looking up collocates. Many students find difficulty figuring out whether a word/phrase could be used academically or not. Using square brackets and the equal sign (=), learners could get synonyms for the word they need with a specific collocate and limit the search to the academic sub corpus. Figure 2 displays the search for synonyms for the word awesome, which should not be used in an academic writing, and the target synonyms should collocate with the word result. The 
academic sub corpus is selected to limit the results. Figure 3 displays the results of the search showing synonymous words for awesome which can collocate with results.

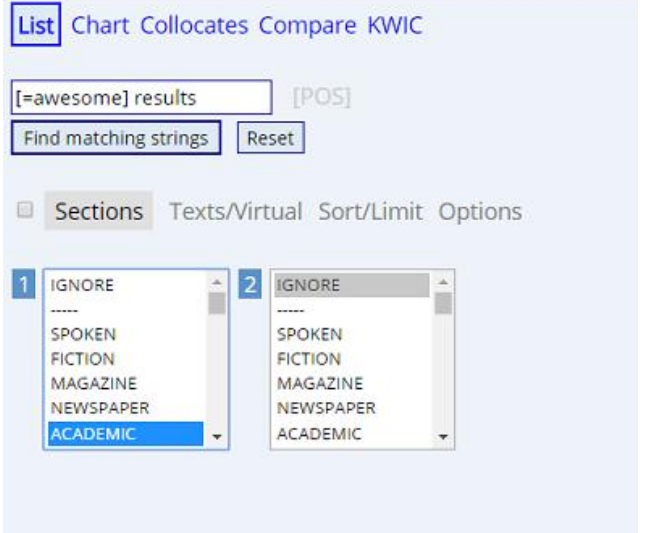

Figure 2. Using the equal sign (=) to look up synonyms and their collocates

\begin{tabular}{c|c|l|c|} 
& & CONTEXT & FREQ \\
\hline 1 & & REMARKABLE RESULTS & 48 \\
\hline 2 & & AMAZING RESULTS & 38 \\
\hline 3 & 0 & TREMENDOUS RESULTS & 10 \\
\hline 4 & $\square$ & ASTOUNDING RESULTS & 5 \\
\hline 5 & $\square$ & SPLENDID RESULTS & 2 \\
\hline 6 & 0 & OVERWHELMING RESULTS & 1 \\
\hline 7 & 0 & BREATHTAKING RESULTS & 1 \\
\hline 8 & $\square$ & AWESOME RESULTS & 1 \\
\hline & & TOTAL & 106 \\
\hline
\end{tabular}

Figure 3. The results of using the search string [=awesome] results

\section{Conclusion}

The use of online corpora as a tool in teaching languages is unlimited; new applications and practices come up every day to serve language pedagogy. COCA is one the richest online resources that could be efficiently used to propose solutions for many pedagogical challenges that face English language teachers and leaners regarding the use of collocations. This papers focused on practical use of search mechanisms and search strings with translation students and academic essay writing students. Both groups have shown significant development of using collocations when they translate academic texts from Arabic into English, or when they write an academic essay. 


\section{References}

Daskalovska, N. (2015). Corpus-based versus Traditional Learning of Collocation. Computer Assisted Language Learning,28(2), 130-144.

Gilmore, A. (2009;2008;). Using online corpora to develop students' writing skills. ELT Journal, 63(4), 363-372. doi:10.1093/elt/ccn056

Jafarpour, A. A., Hashemian, M., \& Alipour, S. (2013). A Corpus-Based Approach toward Teaching Collocation of Synonyms. Theory and Practice in Language Studies, 3(1), 5160. doi:10.4304/tpls.3.1.51-60

Lee, D., \& Swales, J. (2006). A corpus-based EAP course for NNS doctoral students: Moving from available specialized corpora to self-compiled corpora. English for Specific Purposes, 25(1), 56-75. doi:10.1016/j.esp.2005.02.010

Walker, C. (2011). How a corpus-based study of the factors which influence collocation can help in the teaching of business English. English for Specific Purposes,30(2), 101 112. doi:10.1016/j.esp.2010.12.003

Yoon, H. (2008). More Than a Linguistic Reference: The Influence of Corpus Technology on L2 Academic Writing. Language Learning \& Technology, 12(2), 31-48. 